\title{
Determination of sustainable values for the parameters of the construction of residential buildings
}

\author{
Larisa Grigoreva $^{I^{*}}$ and Vladimir Grigoryev ${ }^{2}$ \\ ${ }^{1}$ Moscow State University of Civil Engineering (MGSU), 129337, Moscow, Russia \\ ${ }^{2}$ JSC "Atomtechenergo", Department of Information and Analytical Systems, 101000 Moscow, \\ Russia
}

\begin{abstract}
For the formation of programs for housing construction and planning of capital investments, when developing the strategic planning companies by construction companies, the norms or calculated indicators of the duration of the construction of high-rise residential buildings and multifunctional complexes are mandatory. Determination of stable values of the parameters for the high-rise construction residential buildings provides an opportunity to establish a reasonable duration of construction at the planning and design stages of residential complexes, taking into account the influence of market conditions factors. The concept of the formation of enlarged models for the high-rise construction residential buildings is based on a real mapping in time and space of the most significant redistribution with their organizational and technological interconnection - the preparatory period, the underground part, the above-ground part, external engineering networks, landscaping. The total duration of the construction of a residential building, depending on the duration of each redistribution and the degree of their overlapping, can be determined by one of the proposed four options. At the same time, a unified approach to determining the overall duration of construction on the basis of the provisions of a streamlined construction organization with the testing of results on the example of high-rise residential buildings of the typical I-155B series was developed, and the coefficients for combining the work and the main redevelopment of the building were determined.
\end{abstract}

\section{Introduction}

In Russia, the practice of multi-storey mass housing construction and design standards was previously focused on the height of buildings up to $75 \mathrm{~m}$. At present, high-rise buildings are considered to be above $75 \mathrm{~m}$. According to the number of floors, the existing classifications are rather conventional. Residential buildings are considered high-rise if there are at least 25 floors.

In works $[1,2]$, the authors consider the trends in the development of high-rise construction in Russia. In works [3-5], the authors study the international experience of high-

\footnotetext{
*pehel@yandex.ru
} 
rise construction, identify the features of building technologies and the role of high-rise buildings in the urban space.

The erection of high-rise buildings implies the development of a single regulatory and legal framework [6, 7]. In February 2017, a set of rules «Engineering systems of high-rise buildings» came into effect, which provide for the integrated security of buildings, will improve energy efficiency and reduce the consumption of non-renewable resources in construction and operation. However, these standards do not regulate the duration of construction.

For the organizational and technological design of high-rise construction, there is a need for a system that includes a variety of organizational, technological, technical, economic and time factors and provides the opportunity to regulate the performance indicators $[8,9]$.

The purpose of the work is to study and evaluate the indicators of the duration of construction of residential buildings, the establishment of sustainable indicators of the duration of construction of major stages.

\section{Methods}

To compare and study the parameters of the construction of residential buildings, a statistical array of initial information was collected for typical series of wide application for more than a decade of their construction in Moscow and the Moscow region. The main parameters of the construction of residential buildings are, first of all, indicators of the duration of the construction of the building as a whole and its individual redistribution (stages) - the preparatory period, the main period, including the erection of underground and aboveground parts.

Calculated indicators of the duration of construction of facilities can be determined on the basis of organizational and technological documentation, the degree of object readiness, statistical evaluation of durations [10-12]. In [13], the authors showed that, in general, the reconstruction of high-rise buildings is similar to the reconstruction of other buildings and structures. At the same time, similar steps are used when drawing up a package of design estimates, previous and accompanying work. The main difference is in the choice of schemes for mechanization of dismantling and assembly works of reconstruction and further application of organizational solutions.

\section{Results}

The main indicators of development and adoption of optimization solutions are:

total duration of construction, $\mathrm{T}$;

duration of the preparatory period, $\mathrm{T}_{1}$;

duration of the erection of the underground part, $\mathrm{T}_{2}$;

duration of erection of the above-ground part, $\mathrm{T}_{3}$;

duration of laying of external engineering networks, $\mathrm{T}_{4}$;

duration of improvement, $\mathrm{T}_{5}$.

There are various options for determining the total duration of construction of a residential building. We have identified 4 main options:

Option 1.

$$
\begin{gathered}
T=T_{1}+T_{2}+T_{3}+(1-\alpha) T_{4}+(1-\beta) T_{5} \\
\text { at } T_{4}^{\prime}>T_{3}^{\prime} \text { and } T_{5}^{\prime}>T_{3}^{\prime}
\end{gathered}
$$

where $\mathrm{T}$ is the total duration of the construction of a residential building, days;

$\mathrm{T}_{1}$ - duration of the preparatory period, days;

$\mathrm{T}_{2}, \mathrm{~T}_{3}, \mathrm{~T}_{4}, \mathrm{~T}_{5}$ - duration of erection (device), respectively, of underground, aboveground parts of buildings, external engineering networks, improvement, days; 
$\mathrm{T}_{3}^{\prime}, \mathrm{T}_{4}^{\prime}, \mathrm{T}_{5}^{\prime}$ - date of completion of works, respectively, for erection of the above-ground part, laying of external engineering networks and improvement;

$\alpha$ - the coefficient of overlapping in time of work on the laying of external engineering networks with the erection of the elevated part of the building;

$\beta$ - coefficient of time alignment of works on the improvement of the territory with the erection of the elevated part of the building.

Option 2.

Option 3.

$$
\begin{gathered}
T=T_{1}+T_{2}+T_{3} \\
\text { at } T_{4}^{\prime} \leq T_{3}^{\prime} \text { and } T_{5}^{\prime} \leq T_{3}^{\prime}
\end{gathered}
$$

Option 4.

$$
\begin{gathered}
T=T_{1}+T_{2}+T_{3}+(1-\alpha) T_{4} \\
\text { at } T_{4}^{\prime}>T_{3}^{\prime} \text { and } T_{5}^{\prime} \leq T_{3}^{\prime}
\end{gathered}
$$

$$
\begin{gathered}
T=T_{1}+T_{2}+T_{3}+(1-\beta) T_{5} \\
\text { at } T_{4}^{\prime} \leq T_{3}^{\prime} \text { and } T_{5}^{\prime}>T_{3}^{\prime}
\end{gathered}
$$

More demanded is Option 2, while the work on laying external engineering networks and landscaping are carried out simultaneously with the erection of the elevated part of the residential building. For each option set the duration of each stage, taking into account the identification of rational duration of work and their maximum overlap. For this purpose, for the set of works (Figure 1), the duration of their implementation can be defined as:

$$
t=t_{\mathrm{n}}+\sum_{\mathrm{i}=1}^{\mathrm{n}-1}\left(t_{\mathrm{i}}-\psi_{\mathrm{t}} t_{\mathrm{i}}\right)
$$

where $\mathrm{t}-$ the duration of the whole set of works $\mathrm{i}=\overline{1, n}$;

$t_{n}$ - the duration of the last $n$-th work;

$\mathrm{t}_{\mathrm{i}}-$ the duration of the $\mathrm{i}$-th work, $\mathrm{i}=\overline{1, n}$;

$\Psi_{\mathrm{i}}-$ the coefficient of combination in time $\mathrm{i}$ and $(\mathrm{i}+1)$ works, equal to

$$
\psi_{\mathrm{t}}=\frac{t_{\mathrm{i}+1}^{\mathrm{c}}}{t_{\mathrm{i}}}
$$

where $t_{\mathrm{i}+1}^{\mathrm{c}}$ - duration of the $(\mathrm{i}+1)$ work, of combination with $\mathrm{i}$-th works, $t_{\mathrm{i}+1}^{\mathrm{c}} \leq t_{\mathrm{i}+1}$, substitute the expression for $\Psi_{\mathrm{i}}$ in (3):

$$
t=t_{\mathrm{n}}+\sum_{\mathrm{i}=1}^{\mathrm{n}-1}\left(t_{\mathrm{i}}-t_{\mathrm{i}+1}^{\mathrm{c}}\right)
$$

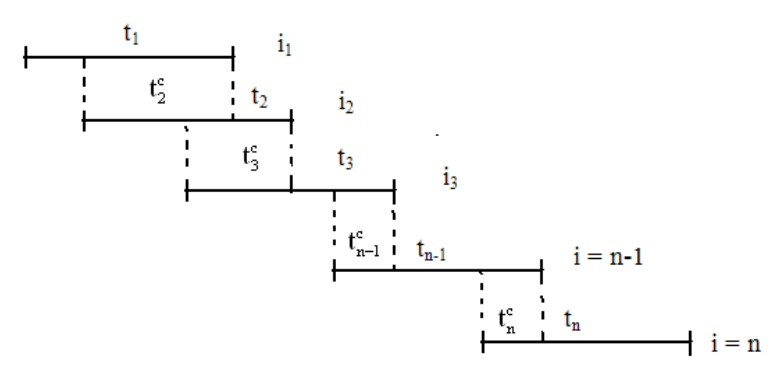

Fig. 1. Fragment of the planned schedule of works 
Residential building series I-155B is a 25 storey single-section tower. Residential buildings of this series can be attributed to high-rise buildings. The duration of the preparatory period $\left(T_{1}\right)$ for both normative documents and actual data is one month $[14,15]$.

The underground part. Terms for the erection of the underground part are made up of the length of the excavation excavation and the device in the combination of a monolithic plate and the zero cycle (Figure 2):

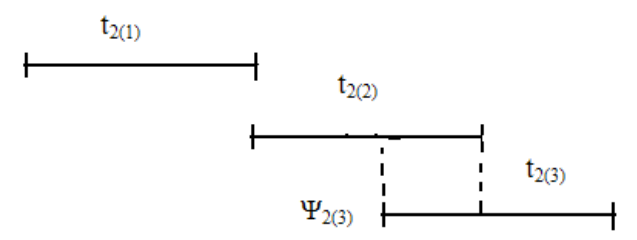

Fig. 2. Fragment of the calendar plan for the erection of the underground part of the residential building $\mathrm{I}-155 \mathrm{~B}$

$$
T_{2}=t_{(2) 3}+t_{(2) 1}+t_{(2) 2}-\Psi_{2(3)} \cdot t_{(2) 2}
$$

$t_{(2) 1}, t_{(2) 2}, t_{(2) 3}$ - the length of the excavation, the device of a monolithic slab, the erection of the technical underground;

$\Psi_{2(3)}$ - coefficient of combination of works on the erection of the technical underground with the device of a monolithic plate, varying within:

$$
\Psi_{2(3)}=\left\{\begin{array}{l}
\frac{5}{24} \div \frac{5}{20}=0,21 \div 0,25 \\
\frac{10}{24} \div \frac{10}{20}=0,42 \div 0,50
\end{array}\right\} \quad 0,21 \leq \Psi_{2(3)} \leq 0,50
$$

at the device of a monolithic plate with pile base:

$$
\Psi_{2(3)}=\left\{\begin{array}{l}
\frac{5}{30} \div \frac{5}{25}=0,17 \div 0,20 \\
\frac{10}{30} \div \frac{10}{25}=0,33 \div 0,40
\end{array}\right\} \quad 0,17 \leq \Psi_{2(3)} \leq 0,40
$$

Installation of the tower crane is carried out in parallel with the excavation of the excavation and therefore does not stand out as a separate type of work.

Thus, the duration of the erection of the underground part of the residential building of the I-155B series will be:

at the device of a monolithic plate without a pile foundation

$$
\begin{array}{r}
\min T_{2}^{\prime}=25+15+20-0,21 \cdot 20=55,8 \text { days } \\
\min T_{2}^{\prime}=35+20+24-0,5 \cdot 20=50,0 \text { days } \\
\min \overline{T_{2}^{\prime}}=52,9 \text { days } \\
\max T_{2}^{\prime}=35+20+24-0,21 \cdot 24=74,0 \text { days } \\
\max T_{2}^{\prime}=35+20+24-0,5 \cdot 24=67,0 \text { days } \\
\max \overline{T_{2}^{\prime}}=70,5 \text { days }
\end{array}
$$

at the device of a monolithic plate with pile base:

$\min T_{2}^{\prime \prime}=25+15+25-0,17 \cdot 25=60,8$ days

$\min T_{2}^{\prime \prime}=25+15+25-0,4 \cdot 25=55,0$ days 


$$
\begin{gathered}
\min \overline{T_{2}^{/ \prime}}=57,9 \text { дн. } \\
\max T_{2}^{/ \prime}=35+20+30-0,17 \cdot 30=79,9 \text { days } \\
\max T_{2}^{/ /}=35+20+30-0,4 \cdot 30=73,0 \text { days } \\
\max \overline{T_{2}^{/ /}}=76,5 \text { days }
\end{gathered}
$$

$\min T_{2}^{\prime}, \max T_{2}^{\prime}$ - duration of the erection of a subterranean part during the construction of a monolithic slab without a pile foundation with values $\Psi=0,21$ и $\Psi=0,50$;

$\min T_{2}^{\prime \prime}, \max T_{2}^{\prime \prime}-$ duration of the erection of a subterranean part when constructing a monolithic slab with a pile base at values $\Psi=0,17$ и $\Psi=0,40$;

$\min \overline{T_{2}^{\prime}}, \max \overline{T_{2}^{\prime}}-$ minimum and maximum average duration of the erection of a subterranean part when constructing a monolithic slab without a pile foundation;

$\min \overline{T_{2}^{/ /}}, \max \overline{T_{2}^{/ /}}-$minimum and maximum average duration of the erection of a subterranean part when constructing a monolithic slab with a pile foundation.

The aboveground part. The erection of the aboveground part includes the following main works: installation of prefabricated reinforced concrete structures, construction, plumbing, electrical and finishing works.

The parameters of assembly of prefabricated reinforced concrete structures have a wide range of values both for the duration of installation and for the number of floors to be mounted (Table 1). At the same time, the maximum duration of assembly of prefabricated reinforced concrete structures is typical for variants with strongly pronounced unevenness of the assembled floors (for example, 1-3-6-7-7-1, 3-4-5-6-6-1).

Table 1. Variants of erecting floors by time periods (fragment)

\begin{tabular}{|c|c|c|c|c|c|c|c|c|}
\hline \multirow{2}{*}{$\begin{array}{c}\text { Cipher } \\
\text { (number) }\end{array}$} & \multicolumn{8}{|c|}{ Number of installed floors by month } \\
\cline { 2 - 9 } & 1 & 2 & 3 & 4 & 5 & 6 & 7 & 8 \\
\hline 69 & 4 & 4 & 6 & 5 & 6 & & & \\
71 & 1 & 6 & 7 & 7 & 4 & & & \\
72 & 1 & 4 & 4 & 8 & 8 & & & \\
73 & 1 & 1 & 4 & 10 & 9 & & & \\
74 & 5 & 9 & 8 & 3 & - & & & \\
75 & 1 & 4 & 8 & 8 & 4 & & & \\
77 & 3 & 8 & 7 & 7 & - & & & 1 \\
79 & 2 & 4 & 3 & 2 & 5 & 4 & 4 & \\
81 & 1 & 3 & 6 & 7 & 7 & 1 & & \\
82 & 3 & 4 & 5 & 6 & 6 & 1 & & \\
83 & 2 & 4 & 6 & 4 & 6 & 3 & & \\
\hline $\begin{array}{c}\text { Total number } \\
\text { of floors }\end{array}$ & 24 & 51 & 64 & 67 & 55 & 9 & 4 & 1 \\
\hline $\begin{array}{c}\text { Average value } \\
\text { of the floors }\end{array}$ & 2 & 4 & 5 & 6 & 6 & 2 & - & - \\
being erected & & & & & & & & \\
\hline
\end{tabular}

Analysis of the options for erecting floors by time periods showed that such a situation arose as a result of the discrepancy between the available labor and material and technical resources to the number of simultaneously erected objects. So, for example, during 2016, the installation of the aboveground part was carried out at 28 sites. At the same time, the maximum volume of installed floors falls on November and December, respectively, at 63 
and 56 floors. In January, only 29 floors were erected, and in the remaining months the number of mounted floors ranged from 35 to 50 .

To obtain statistical values of the duration of installation of prefabricated reinforced concrete structures of the above-ground part of the residential building I-155B, an array of initial information is formed, in which $\underline{t}-$ the duration of montage of $\mathrm{n}$-floors (months), $t_{0}-$ the duration of one-storey installation (month), $\mathrm{n}-$ the number floors (Table 2).

Table 2. Statistics on the installation of residential buildings I-155B

\begin{tabular}{|l|l|l|l|l|l|l|l|l|l|l|l|}
\hline $\mathrm{n}$ & 3 & 2 & 8 & 16 & 22 & 23 & 25 & 24 & 25 & 25 & 25 \\
\hline$\underline{t}$ & 1 & 1 & 2 & 4 & 6 & 6 & 5 & 5 & 5 & 5 & 5 \\
\hline$t_{0}$ & 0.33 & 0.50 & 0.25 & 0.25 & 0.27 & 0.26 & 0.26 & 0.20 & 0.21 & 0.20 & 0.20 \\
\hline $\mathrm{n}$ & 25 & 25 & 15 & 25 & 17 & 25 & 13 & 25 & 25 & 25 & \\
\hline$\underline{t}$ & 4 & 5 & 3 & 4 & 3 & 8 & 2 & 6 & 6 & 6 & \\
\hline$t_{0}$ & 0.16 & 0.20 & 0.20 & 0.16 & 0.18 & 0.32 & 0.15 & 0.24 & 0.24 & 0.24 & \\
\hline
\end{tabular}

After processing of the specified data array, the following equations of communication were obtained between the duration of installation of prefabricated reinforced concrete structures and the number of installed floors:
linear
quadratic
$\mathrm{t}=0,25+0,21 \cdot \mathrm{n}$
logarithmic

$$
\begin{gathered}
\mathrm{t}=0,57+0,14 \cdot \mathrm{n}+0,22 \cdot 10^{-2} \cdot \mathrm{n}^{2} \\
\mathrm{t}=1,49+2,07 \cdot \log \mathrm{n} .
\end{gathered}
$$

Calculation of linear dependence: the regression $t=\mathrm{f}(n)$ has the form $t=k \cdot n+b$, where $\mathrm{k}, \mathrm{b}$ are coefficients.

$$
k=\frac{\overline{t \cdot n}-\bar{t} \cdot \bar{n}}{D_{n}}=\frac{98,667-19,905 \cdot 4,381}{55,23}=0,207
$$

$\bar{t}=4,381 \quad-$ mathematical expectation $t$

$\bar{n}=19,905 \quad$ mathematical expectation $n$;

$\overline{t \cdot n}=98,667-$ mathematical expectation $t \cdot n$;

$\mathrm{D}_{\mathrm{n}}-$ dispersion $\mathrm{n}, \mathrm{D}_{\mathrm{n}}=55,23 ; b=\bar{t}-k \cdot \bar{n}=4,381-0,207 \cdot 19,905=0,249$

Thus, the equation of linear dependence has the form $\mathrm{t}=0,25+0,21 \cdot \mathrm{n}$.

To determine the relationship, the correlation coefficient is calculated by the following formula:

$$
\begin{gathered}
r=\frac{\overline{t \cdot n}-\bar{t} \cdot \bar{n}}{S_{n} \cdot S_{t}} \\
\mathrm{~S}_{\mathrm{n}}-\text { standard deviation } n ; \quad \mathrm{S}_{\mathrm{t}}-\text { standard deviation } t \\
r=\frac{98,667-4,381 \cdot 19,905}{7,432 \cdot 1,785}=0,864
\end{gathered}
$$

Similar calculations were made for the quadratic and logarithmic functions.

Linear regression is better than quadratic and logarithmic approximates the relationship between the duration of installation of prefabricated reinforced concrete structures and the number of installed floors: Correlation coefficient for linear dependence -0.864 ; Correlation coefficient for quadratic dependence - 0,833; Correlation coefficient for the logarithmic dependence $-0,649$.

Based on the analysis of design and practical solutions, the following important circumstance is revealed: the duration of erection of the aboveground part can be defined as 
the arithmetical sum of the installation time of prefabricated reinforced concrete structures, the incompatible part of the plumbing work, the incompatible part of the finishing works.

All other types of work are carried out within the specified total duration of erection of the aboveground part.

In the case of different lengths of performance of plumbing and electrical work, the maximum duration is assumed.

Thus, the duration of erection of the above-ground part is represented as $T_{3}=t_{3(1)}+t_{3(2)}+t_{3(3)}-\Psi_{3(2)} \cdot t_{3(2)}-\Psi_{3(3)} \cdot t_{3(3)}$

$t_{3(1)}, t_{3(2)}, t_{3(3)}-$ duration, respectively, installation of prefabricated reinforced concrete structures, performance of sanitary (or electrical), finishing works;

$\Psi_{3(2)}$ - coefficient of combination of plumbing works with the installation of prefabricated reinforced concrete structures;

$\Psi_{3(3)}$ - coefficient of combination of finishing and plumbing (or electrical) work.

The indicators $\Psi_{3(2)}, \Psi_{3(3)}$ ) will be applied within the following limits:

$$
\begin{gathered}
\Psi_{3(2)}=\left\{\begin{array}{l}
\psi_{3(2)}^{\prime}=\frac{15}{165} \div \frac{15}{120}=0,09 \div 0,13 \\
\psi_{3(2)}^{\prime \prime}=\frac{30}{165} \div \frac{30}{120}=0,18 \div 0,25
\end{array}\right\} \quad 0,09 \leq \Psi_{3(2)} \leq 0,25 \\
\Psi_{3(3)}=\left\{\begin{array}{l}
\psi_{3(3)}^{\prime}=\frac{80}{180} \div \frac{80}{150}=0,44 \div 0,53 \\
\psi_{3(3)}^{\prime \prime}=\frac{100}{180} \div \frac{100}{150}=0,56 \div 0,67
\end{array}\right\} \quad 0,44 \leq \Psi_{3(3)} \leq 0,67
\end{gathered}
$$

The duration of erection of the above-ground part is multivariant, therefore it can be represented as an interval of values between the minimum and maximum limits, i.e.

$$
\min \mathrm{T}_{3} \leq \mathrm{T}_{3}<\max _{3}
$$

In Table 3, only the minimum and maximum performance indicators are presented and therefore all intermediate values of $\mathrm{T}_{3}$ will be in the interval 265.5 days $\leq \mathrm{T}_{3} \leq 393.2$ days.

Table 3. Indicators for the duration of erection of the aboveground part depending on the duration and degree of overlap

\begin{tabular}{|c|c|c|c|c|c|}
\hline \multicolumn{4}{|c|}{ Key performance indicators, days } & $\begin{array}{c}\text { Duration indicator } \\
\text { erection of the aboveground part, days }\end{array}$ \\
\hline $\mathrm{t}_{3(1)}$ & $\mathrm{t}_{3(2)}$ & $\mathrm{t}_{3(3)}$ & $\Psi_{3(2)}$ & $\Psi_{3(3)}$ & $\mathrm{T}_{3}$ \\
\hline 1 & 2 & 3 & 4 & 5 & 6 \\
\hline 120 & 150 & 100 & 0,09 & 0,44 & 312,5 \\
120 & 150 & 100 & 0,25 & 0,44 & 288,5 \\
120 & 150 & 100 & 0,09 & 0,67 & 289,5 \\
120 & 150 & 100 & 0,25 & 0,67 & 265,5 \\
& & & & & \\
165 & 180 & 115 & 0,09 & 0,44 & 393,2 \\
165 & 180 & 115 & 0,25 & 0,44 & 364,4 \\
165 & 180 & 115 & 0,09 & 0,67 & 366,8 \\
165 & 180 & 115 & 0,25 & 0,67 & 338,0 \\
\hline
\end{tabular}




\section{Conclusions}

The total duration of the construction of a residential building, depending on the duration of each redistribution and the degree of their overlapping, can be determined from one of the identified four options.

Approaches are proposed for determining the duration of the erection of underground and aboveground parts of residential buildings, taking into account the wide spread, both the duration of their work, and the degree of their overlap with the indication of the minimum and maximum values and conditions for their operation. So, for example, for residential buildings I-155B the coefficients of combination of works during the device of technical underground vary in the range from 0.17 to 0.50 with the duration of erection of the underground part from 52.9 days. up to 76.5 days, and when erecting the above-ground part, the coefficients of work combination vary from 0.09 to 0.67 with the duration of this redistribution from 265.5 days. up to 393.2 days.

When forecasting and planning the residential development of neighborhoods and neighborhoods, a simplified approach can be used to determine the total duration of construction of residential buildings, based on the statistical relationship between the duration of construction and the total area.

\section{References}

1. A. Magay, Housing construction, 2, 9-12 (2008)

2. O. Zhuchkov, E. Marinich, S.Turmov, Mod. soc.: probl., ideas, innov., 4, 8993(2015)

3. T. Maklakova, High-rise buildings. Urban planning and architectural and constructive design problems (Moscow, Publisher ASV, 2008)

4. A. Matejko, Vestnik SGASU, 3, 74 (2016)

5. A. Kozhas, M. Rakhimov, A. Kasimov, S. Kozhasov, Proc. of the University, 3 (60), (2015)

6. E. Generalova, K. Galstyan, Traditions and innovations in construction and architecture. Architecture and design (Samara, 2015)

7. A. Bimagambetov Bull. of scien. conferences, 4-1 (8), (2016)

8. T. Kravchunovska, E. Zajats, S. Yepifantseva, Prydniprovs'ka State Academy of Civil Engineering and Architecture, 11 (176), 4-8 (2012)

9. V. Bolshakov, T. Kravchunovska, E. Zayats, S. Yepifantseva, Prydniprovs'ka State Academy of Civil Engineering and Architecture, 10 (175), 4-9 (2012)

10. P. Panchenko, T. Bobrova, The assessment of the duration of the installation work in the construction of buildings on the basis of the valuation technological operations (Omsk, 2016)

11. A. Bronevitsky, S. Bronevitsky, Prydniprovs'ka State Academy of Civil Engineering and Architecture, 11-12 (164-165), 40-45 (2011)

12. S.A. Bolotin, A.Kh. Dadar, I.S. Ptuhina, Engin. and constr. magazine, 7(25), 82-86 (2011)

13. YU. Kontorchyk, B. Zakorko, Prydniprovs'ka State Academy of Civil Engineering and Architecture, 4 (205), 55-61 (2015)

14. SNiP 1.04.03-85. The norms of the duration of construction and the backlog in the construction of enterprises, buildings and structures. 
15. Regional standards for the duration of construction of buildings and structures in the city of Moscow (SUE "NIAC", 2007) 